\title{
Bioética e saúde coletiva: convergências epistemológicas
}

\author{
Bioethics and public health: epistemological convergences
}

Jose Roque Junges ${ }^{1}$

Elma Lourdes Campos Pavone Zoboli ${ }^{2}$

${ }^{1}$ Programa de Pós Graduação Em Saúde Coletiva, Universidade do Vale do Rio dos Sinos. Av. Unisinos 950, Cristo Rei. 93022-000 Sao Leopoldo RS. roquejunges@hotmail.com ${ }^{2}$ Departamento de Enfermagem Em Saúde Coletiva, Universidade de São Paulo.

\begin{abstract}
This is a theoretical discussion about the epistemological statute of bioethics based on its convergences with public health, linked as scientific areas that came from the context of the second epistemological rupture, which questioned the critique to common sense inherent in modern science. The reapproximation with common sense in the second rupture means considering the determinants of environment and subjectivity in the methodology. Emerging from the second rupture, public health and bioethics include the social and subjective determinants in their anal$y$ sis, with an enlarged and complex vision of human health and human actions involving environment, life and health. This requires a transdisciplinary focus in their approaches. What is the meaning of these premises for the epistemological statute of bioethics in its convergence with public health? As ethics, bioethics needs to be critical, but not aprioristic. The criticism of bioethics needs to come from the facticity of the social determinants expressed by the health iniquities. The only way to integrate criticism and facticity is hermeneutics, interpreting the significances constructed in the reality and become critical therefrom. This is the epistemological statute appropriate to bioethics in its convergence with public health.
\end{abstract}

Key words Public health, Bioethics, Epistemology, Complexity, Hermeneutics
Resumo Trata-se de uma discussão teórica sobre o estatuto da bioética a partir de suas convergências epistemológicas com a saúde coletiva, campos científicos inter-relacionados, surgidos no contexto da segunda ruptura epistemológica, questionadora da crítica ao senso comum própria da ciência moderna. A reaproximação com o senso comum na segunda ruptura significa considerar na metodologia os determinantes do ambiente e da subjetividade. Assim, em meio a esta segunda ruptura, a saúde coletiva e a bioética incluem os determinantes sociais e subjetivos em suas análises. Caracterizam-se por uma visão ampliada e complexa da saúde e das ações humanas envolvendo o ambiente, a vida e a saúde, com enfoque transdisciplinar em suas abordagens. Qual o significado dessas premissas para o estatuto epistemológico da bioética em sua convergência com a saúde coletiva? Enquanto ética, a bioética precisa ser crítica, mas não como na primeira ruptura da filosofia moral. Necessita ser crítica a partir da facticidade dos determinantes sociais que se manifestam nas iniquidades em saúde. Para integrar crítica e facticidade, o caminho é a hermenêutica que interpreta os significados construídos no real e a partir deles torna-se crítica. Esse seria o estatuto epistemológico apropriado para a bioética na interface com a saúde coletiva.

Palavras-chave Saúde coletiva, Bioética, Epistemologia, Complexidade, Hermenêutica 


\section{Introdução}

A proposta de Potter ${ }^{1}$ era de bioética com forte perspectiva ecológica, mas a que acabou por se impor na produção científica marcou-se pelo acento clínico e preocupação com a introdução e a aplicação das inovações biotecnológicas à saúde. Os problemas éticos reduziram-se às relações do médico com paciente ou do pesquisador com sujeito de pesquisa, resolvendo-se pela aplicação mecânica dos princípios da autonomia, beneficência e justiça. A falta da dimensão ambiental enfraqueceu o enfoque ecológico e social, impedindo a visão sistêmica dos problemas tratados pela bioética.

No Brasil, também se dá a mesma redução, a despeito de uma "origem sanitária da bioética" decorrente, em boa parte, de sua afirmação nos anos 90 ao se legitimar em campo científico e acadêmico com destacado interesse na saúde pública e saúde coletiva ${ }^{2}$.

Mas a proximidade entre a bioética e a saúde coletiva sem a devida fundamentação teórica da relação entre ambos campos de conhecimentos e práticas pode comprometer as potencialidades desta aproximação devido a uma possível confusão entre o sujeito epistêmico e o sujeito ético, já que não existe, em bioética, uma continuidade entre saber algo e pô-lo em prática ${ }^{3}$.

Urge, então, explorar as convergências epistemológicas, metodológicas e distinguir as especificidades de pontos de vista da bioética e da saúde coletiva. O propósito do artigo, de enfoque epistemológico, é fundamentar teoricamente a relação entre esses campos de conhecimento, para, a partir da especificidade de seus saberes, apontar as convergências epistemológicas.

\section{Campo Científico}

O conceito de campo científico, de Bourdieu, significa um sistema de relações objetivas no âmbito da ciência, definidas por posições adquiridas de poder em confronto a posições anteriores. Está em jogo o monopólio da autoridade científica identificada com a capacidade técnica e poder social ou o monopólio da competência científica, enquanto capacidade de falar e agir legitimamente outorgada pela sociedade a um determinado agente. Assim, os campos científicos são mais definidos pelas articulações epistemológicas dos sujeitos defensores de determinado saber do que pela objetividade epistemológica de seus axiomas e conteúdos. Essa visão rompe com uma compreensão de campo científico como rei- no desinteressado de fins onde impera apenas a perfeita concorrência da verdade das ideias. $\mathrm{Ou}$ seja, ele produz e supõe uma forma específica de interesse. Portanto, todo campo científico funda-se num interesse científico e se baseia numa autoridade ou competência científicas ${ }^{4}$.

Com essa compreensão, como referência, entendemos que a bioética e a saúde coletiva constituíram-se como campos científicos, no Brasil, na luta pela consolidação de poder científico, levada a cabo por suas respectivas entidades de representação: a Sociedade Brasileira de Bioética (SBB) e a Associação Brasileira de Saúde Coletiva (Abrasco).

A saúde coletiva implicou avanços frente à saúde pública ao caracterizar-se como conjunto de diferentes saberes que dão suporte às práticas de distintas categorias e aos atores sociais face às questões de saúde/doença e à organização da assistência com referência à dimensão social e ambiental do processo de saúde e doença ${ }^{5}$.

Revisando o tema, Nunes ${ }^{6}$ afirma que a saúde coletiva estabelece crítica ao universalismo naturalista do saber médico e rompe com a concepção de saúde pública, negando monopólio do discurso biológico.

A saúde coletiva é entendida como campo científico, onde se produzem saberes e conhecimentos acerca do objeto 'saúde' e onde operam distintas disciplinas que o contemplam sob vários ângulos, e como prática social, onde se realizam ações em diferentes organizações e instituições por diversos agentes (especializados ou não) dentro e fora do espaço convencionalmente reconhecido como 'setor saúde's. Portanto, como campo de saber específico, a saúde coletiva acontece tanto ao nível do discurso científico como das práticas sociais.

A bioética constituiu-se como campo científico, distinguindo-se da ética filosófica encastelada em abstracionismos linguísticos que a afastavam dos problemas morais concretos e diferenciando-se da mera ampliação da ética médica. Nessa luta epistemológica, afirmou-se como ética aplicada e fórum de discussão pluralista e transdisciplinar empenhado na inclusão de questões ambientais e problemáticas sociais da saúde. Epistemologicamente, não se reduziu a pura casuística e se constituiu, também, como discurso científico e hermenêutica crítica das práticas em saúde. Essa identidade aproxima-a da saúde coletiva, ao definir-se tanto como discurso científico e como proposta para pensar, compreender situações práticas no sentido de propiciar tomada de decisões mais apropriadas, ou seja, 
mais adequadas à complexidade e à incerteza das situações da realidade.

Ambas se aproximam, ainda, pela inclusão de diversos campos do conhecimento para a compreensão de seus objetos. A bioética, para a compreensão moral das ações humanas no âmbito da vida e da saúde, além da filosofia, faz valer a sociologia, a antropologia, a psicologia e a comunicação, e incorpora estudos empíricos, quantitativos e qualitativos do agir moral em saúde. A ética é componente essencial do processo saúde-doença-cuidado e sua compreensão precisa incluir a realidade material das ações, numa convergência com a saúde coletiva.

\section{Dupla ruptura epistemológica}

Para aprofundar a compreensão da saúde coletiva e da bioética como campos científicos, introduzimos o conceito da dupla ruptura epistemológica proposto por Boaventura Santos ${ }^{7}$ na esteira de Bachelard ${ }^{8}$. A primeira ruptura acontece quando a ciência rompe com a opinião e o senso comum. A ciência constrói-se contra o conhecimento vulgar e espontâneo, contra a experiência imediata e evidente. Quebra as evidências cotidianas e seu 'código de leitura'.

O modelo biomédico significou uma ruptura com as terapêuticas tradicionais do senso comum produzidas na comunidade, fundadas em observação e em práticas de longa data. O relatório de Flexner, almejando fundar a medicina científica calcada na fisiologia e na patologia, foi marco simbólico dessa ruptura. O paradigma clínico foi base para a constituição da ciência médica.

Entretanto, uma contradição permaneceu sem solução: por estar atravessada fundamentalmente pela subjetividade do paciente, a clínica aproxima-se mais da arte do que da ciência. Equivale ao universal, expresso em uma patologia (a tuberculose), mas encarnada, concretizada numa situação particular, em uma pessoa específica, com sua biografia (será o José com tuberculose e a tuberculose do José). A medicina de evidências propõese a superar tal impasse, atingindo o patamar de ciência dura9 ${ }^{9}$. Porém, destarte de todo instrumental científico disponível, a clínica ainda guarda considerável porção intuitiva, dependente das habilidades de seus artistas: usuário e profissional.

A ética pode ser entendida como uma reflexão sobre os costumes ao analisar criticamente o senso comum da moral vigente. A moral é o conjunto de princípios, normas e valores de determinada cultura que orienta como cada um deve- ria se comportar em sociedade. Ética é o saber científico que reflete sobre as morais, criando um distanciamento crítico. A pergunta básica da moral é o que devemos fazer e a questão central da ética é por que devemos fazer ${ }^{10}$.

Os tempos pós-modernos exigem romper com a primeira ruptura epistemológica, pois o saber científico pretende tornar-se senso comum, provocando o reencontro entre ambos e impondo a transformação na própria ciência, a par com a que aconteceu no senso comum. Isso significa que uma vez feita a ruptura epistemológica, o ato epistemológico mais importante é a ruptura com a ruptura epistemológica ${ }^{7}$.

A primeira ruptura responde a pergunta: para que queremos senso comum, separando o conhecimento científico do conhecimento do senso comum? Só existe ciência na confrontação e na crítica da realidade com vistas à sua transformação. $\mathrm{E}$ esta só acontece se o conhecimento científico tornar-se senso comum transformado. Eis, para San$\operatorname{tos}^{7}$, a segunda ruptura epistemológica, que responde à pergunta: para que queremos a ciência?

O discurso metodológico de qualquer ciência identificava-se classicamente com o método das ciências naturais, para o qual a realidade manifestava-se em linguagem matemática, base do positivismo científico. A questão metodológica responde à pergunta como se faz ciência? O construtivismo, ao defender que a realidade constróise na linguagem, significou crítica radical ao realismo positivista e provocou a crise do moderno paradigma científico com a reaproximação da ciência e do senso comum. A crise paradigmática provocada pelo construtivismo impôs a necessária distinção entre os campos teórico e da observação, entre objetos teórico e empírico. Assim, superada a inocência empirista do acesso ao objeto verdadeiro, o caminho metodológico dificultou-se, exigindo pluralidade de métodos e acessos à realidade. Por fim, a hermenêutica crítica da crise colocou a exigência da reflexividade do próprio cientista, exigência antes camuflada pelo consenso positivista da objetividade científica que excluía a subjetividade. Essa autorreflexão do agir do cientista integra a desdogmatização da ciência. É o sinal mais dramático da crise do paradigma científico. Significa que o sujeito epistêmico analisa a si mesmo como sujeito empírico, examinando os instrumentos científicos usados, a comunidade científica que integra e a sociedade da qual é membro ${ }^{7}$.

A saúde coletiva e a bioética, como campos científicos pós-modernos, surgem no âmbito da segunda ruptura epistemológica. 
A biomedicina como modelo científico surgiu na ruptura com as formas tradicionais de terapias, tidas como não científicas por serem fruto de práticas populares de cura das doenças. Configurou-se a partir da revolução microbiana que definiu as doenças como entidades a serem combatidas. Com essa ontologização da enfermidade perdeu-se a visão ecológica da saúde e da doença. A saúde coletiva surge como inovação no campo científico por considerar os determinantes sociais e ambientais do processo saúde/ doença e entender que o diagnóstico e a terapêutica dependem, grandemente, do contexto sociocultural, reaproximando, assim, saber médico e senso comum. A saúde coletiva aparece no contexto da ruptura com a primeira ruptura epistemológica feita pela biomedicina. Esta segunda ruptura reconcilia a clínica com o subjetivo e o social da saúde e da doença, representado pelo senso comum negado na primeira ruptura.

A bioética também surge no âmbito da segunda ruptura epistemológica, pois significa o rompimento com uma ética reduzida à análise da linguagem, típica da filosofia moral do mundo anglo-saxão da primeira metade do século $\mathrm{XX}^{11}$. A aplicação rigorosa da metodologia linguística como caminho de ruptura com a moral convencional restringiu a ética a puro formalismo linguístico, afastando-a dos problemas concretos e da ação real das pessoas. As éticas aplicadas ${ }^{12}$, entre elas a bioética, significaram reação a esse formalismo e ruptura epistemológica com a primeira ruptura, numa reaproximação da ética com o senso comum da moralidade e com as questões morais da vivência cotidiana.

A primeira ruptura epistemológica guiou-se pelo discurso metodológico que rompia com a percepção do senso comum ao reduzir a realidade a elementos controláveis e a excluir a variedade e a desordem, por não poderem se agrupar em um denominador comum e ordenado. Assim, o método simplificava a realidade em objetos científicos desprovidos das particularidades da experiência cotidiana. A primeira ruptura significou a disciplinarização e a compartimentalização do conhecimento científico.

A segunda ruptura epistemológica exprime a introdução da hermenêutica crítica quanto à primeira, devido à reaproximação com o senso comum que devolve a perspectiva da complexidade à análise da realidade e reintegra as intercorrências da subjetividade e as interdependências do contexto na abordagem científica. A saúde coletiva e a bioética surgem no bojo dessa hermenêutica crítica à primeira ruptura epistemológica, demandando olhares complexos e transdisciplinares a seus objetos.

Isto implica que a bioética, reconhecendo a cisão entre a ciência, como produção do conhecimento biológico e a reflexão ética, propõe-se a superá-la, traçando pontes entre o 'bios' e as 'humanidades' com vistas à sobrevivência da humanidade. Assim, de fruto engendrado em meio a uma concepção positivista da produção do conhecimento biológico e em saúde, a bioética vai se remetendo a posturas mais hermenêuticas a fim de dar conta de sua arrojada proposição: integrar ambas áreas do conhecimento em uma só esfera de reflexão, discussão e produção científica. É no bojo dessa trajetória que a bioética passa a incorporar, em sua agenda, temáticas como a justiça em saúde, equidade, saúde das populações, determinantes sociais da saúde e doença, vulnerabilidade na pesquisa clínica internacional.

Ambos saberes, bioética e saúde coletiva, convergem para temáticas essencialmente complexas e transdisciplinares: os campos da saúde e das ações humanas, conformados por interdependências e inter-relações no bojo do entorno social e ambiental. A abordagem transdisciplinar, exigida para a compreensão complexa da realidade, faz da saúde coletiva e da bioética campos integradores de conhecimentos de diferentes áreas, com especial atenção ao contexto.

\section{Complexidade}

A transdisciplinaridade insere-se no contexto maior do paradigma da complexidade, resposta à crise do paradigma cartesiano das ideias claras e distintas. O método científico cartesiano consiste em analisar, distinguir e separar para chegar aos elementos formadores da realidade. Disso resulta a perda da visão de conjunto, eliminando o que não for claro e distinto. A explicação da organização do todo não é captada pelo caminho analítico, pois o ruído, a desordem ou a contradição são excluídos como alheios à realidade.

O pensamento da complexidade propõe-se a obviar tais deficiências do cartesianismo e se caracteriza pelos desafios ${ }^{13}$ : não eliminar o acaso, a desordem e a incerteza da compreensão da realidade, pois são partes da evolução do universo e necessários ao equilíbrio dinâmico da realidade; superar a abstração universalista da ciência moderna que elimina a singularidade, a localidade e a historicidade, pois a biologia atual e a física quântica apontam a importância desses elementos; atentar para a complexidade da realidade, 
pois os fenômenos biológicos e sociais apresentam número incalculável de interações e interretroações, numa fabulosa mistura impossível de ser calculada pelo mais potente computador.

Há uma relação complementar, embora antagônica, entre as noções de ordem, desordem e organização, ou seja, a ordem pode nascer da agitação ou da turbulência desordenadas. A organização é o que constitui, ao mesmo tempo, unidade e multiplicidade; corresponde à complexidade lógica da unitas complex, isto é, a entender o múltiplo no uno e o uno no múltiplo. Assim, é preciso ter sempre presente esse entendimento complexo da realidade. O holograma é a imagem física de que as qualidades da matéria devem-se a que cada um dos seus pontos inclui quase toda informação do conjunto a que representa. Na biologia, cada célula tem a informação genética do ser global. Pode-se dizer, então, que a parte está no todo e o todo, na parte.

Isso leva à crise dos conceitos fechados e claros, à crise da clareza e da separação das explicações próprias da visão cartesiana. Não há verdades claras e distintas, nem demarcações claras entre ciência e não-ciência, objeto e meio, ser vivo e seu ambiente natural, ser humano e seu contexto, sujeito e objeto. Daí a importância de reintroduzir o observador na observação, superando a ilusão de que a objetividade científica somente seria possível com a eliminação do sujeito da observação. Eis a questão central da ética do conhecimento.

Os princípios do paradigma da complexidade, segundo Morin ${ }^{14}$, são:

1) Princípio sistêmico ou organizacional relaciona o conhecimento das partes ao conhecimento do todo, pois o todo é mais que a soma das partes.

2) Princípio hologramático - põe em evidência que o todo é mais que as partes e está inscrito em cada parte.

3) Princípio do circuito retroativo - rompe com a causalidade linear, pois o efeito também retroage sobre a causa em processos autorreguladores.

4) Princípio do circuito recursivo - ultrapassa o princípio anterior da autorregulação e introduz a autoprodução e auto-organização pelas quais cria-se um circuito gerador de produtos e, também, dos próprios produtores e causadores do produzido.

5) Princípio da autonomia/dependência - os seres vivos, como auto-organizados/organizadores, autoproduzem-se retirando energia, informação e organização do meio para manterem sua autonomia.
6) Princípio dialógico - une, como indissociáveis na mesma realidade, noções que sempre se excluíram reciprocamente. Não se trata de superar a contradição, mas mantê-la em tensão numa concepção dialógica entre ordem/equilíbrio-desequilíbrio/desordem e organização.

7) Princípio da reintrodução do conhecimento ou do próprio observador - restaura o papel do sujeito no processo do conhecimento, exigindo contínuas avaliação e reforma do pensamento pela tomada de consciência dos pressupostos do seu paradigma de conhecimento.

Para o paradigma da complexidade, há aspectos essenciais da realidade não captados pelo método clássico da ciência moderna, pois são dimensões que ultrapassam o que as diferentes disciplinas fragmentadas conseguem visualizar. São exemplos: as inter-relações e as interdependências das partes entre si; o sistema que dá unidade a um todo organizado; a íntima relação entre a auto e a eco-organização dos seres vivos e sua autoprodução; a retroação do efeito sobre a causa; a relação complementar e antagônica entre ordem e desordem.

A insuficiência na percepção da realidade para conhecimento do universo, da natureza e dos seres vivos torna-se mais grave no conhecimento sobre o ser humano, que detém complexidade muito maior como ente biocultural. O fracionamento disciplinar mostra-se reducionista e falseador da realidade humana ${ }^{15}$.

Esse reducionismo aparece na concepção de saúde como ausência de doença. Não é tão simples opor saúde e doença, pois não são estados excludentes já que há fatores de ordem e desordem, vida e morte constituintes do processo saúde/doença. Para captar a complexidade desse processo, Almeida ${ }^{16,17}$ propõe o conceito de "integrais de saúde-enfermidade" como rede complexa composta por dimensões de patogênese e salutogênese, pela qual continuamente produzse saúde e doença. Os fatores que influenciam na dinâmica saúde/doença são de ordens biodemográfica e sociocultural, formando um processo que Almeida ${ }^{18}$ chamou de holopatogênese. Este resulta da oposição entre forças de doença, ou holopatógenos, e redutores das vulnerabilidades. Em outras palavras, forças de doença e saúde, pulsões de morte e vida. Isso significa assumir a perspectiva complexa da ordem e desordem na compreensão da saúde.

Essa abordagem complexa da saúde parte da compreensão do ser humano como simultaneamente biológico, social, cultural e simbólico. Com essa visão, Samaja ${ }^{19,20}$ fundamenta sua teoria da 
reprodução social da saúde, explicitando as relações entre saúde e condições de vida, entre saúde e ambiente. Para ele, as ciências da saúde têm por objeto "os encontros e as transações entre diversos espaços de valorações e regulações dos problemas que a reprodução social apresenta em todas as esferas da sociabilidade humana: biossocial, sociocultural, econômico-societal e a ecológica-política"19.

Assim, o objeto saúde compreende as concepções e práticas sanitaristas das esferas biocomunal (reprodução biológica e ambiental), comunal-cultural (reprodução da consciência e da conduta), societária (reprodução associativa e econômica) e estatal (reprodução ecológico-política). O foco da saúde na reprodução social das condições de vida ultrapassa o espaço disciplinar da medicina para englobar uma epidemiologia ecológica, antropológica, sociológica, jurídica, econômica e ambientalista. As condições de vida determinam as situações de saúde e estas devem ser estudadas na perspectiva dos elementos biológicos, sociais, culturais e simbólicos daquelas ${ }^{19,20}$.

A interferência de fatores bio-sócio-culturais na constituição da saúde permite entendê-la como autopoiese e auto-organização na perspectiva do paradigma da complexidade. Assim, saúde é a capacidade de reagir aos diversos fatores que vulnerabilizam o equilíbrio vital, a fim de reorganizar, na subjetividade e em interação com o contexto socioambiental, os elementos biológicos, psicológicos e simbólicos. Saúde é a capacidade de autorrefazer-se ou de auto-organizarse como sujeito e depende, essencialmente, da articulação entre subjetividade e ambiente.

O reducionismo da compreensão do processo saúde/doença decorre dos pressupostos do método científico adotado na clínica e na epidemiologia em consequência da primeira ruptura epistemológica. A saúde coletiva propõe-se como superação desse reducionismo e reintroduz a perspectiva complexa da subjetividade e do contexto sociocultural na interpretação da saúde e da doença. A etnoepidemiologia ou epidemiologia complexa de Almei$\mathrm{da}^{16}$ e a antropoclínica ou clínica ampliada de Cam$\operatorname{pos}^{21}$ e Cunha ${ }^{22}$ são intentos na linha hermenêutica da segunda ruptura epistemológica.

A bioética, igualmente fruto da segunda ruptura epistemológica, marcada pela hermenêutica, também assume o enfoque complexo na abordagem de seu objeto, as ações humanas relativas à vida, à saúde e ao ambiente. Define-se como ética complexa, que supera a simples ruptura crítica com o senso moral comum, abarcando as tensões próprias das ações humanas ${ }^{23}$.
Uma dessas tensões dá-se entre sujeito e comunidade. Ao invés de privilegiar um deles, devese compreendê-los em confronto dialógico. O princípio egocêntrico de exclusão que garante a identidade singular de cada indivíduo em seus interesses particulares e o princípio altruísta da inclusão que acentua a relação com os outros e a inserção numa fraternidade (como espécie, sociedade e humanidade) precisam ser tomados em suas inter e retrodependências.

$\mathrm{Na}$ ação, acontece o confronto dialógico entre a singularidade da intencionalidade subjetiva e a universalidade da norma social. Só assim é possível conceber conjuntamente as duas condições básicas para a moralidade: a autonomia do sujeito e a responsabilidade perante os outros, religando o que vinha separado: o sujeito e a sociedade. Como diz Morin ${ }^{23}$, todo olhar sobre a ética deve reconhecer o aspecto vital do egocentrismo assim como a potencialidade fundamental do desenvolvimento do altruísmo.

Essa primeira tensão aponta para uma segunda: a dimensão autológica e ecológica da ação. Isso significa que, contrariamente à opinião que enraíza a ação no autor, entende-se que a ação escapa à intenção de seu autor, para amortecerse nas retroações negativas e acarretar retroações positivas inesperadas. Assim, a ação pertence mais aos processos ecológicos do que às decisões autológicas; escapa da voluntariedade do ator, para se amalgamar nas inter-retroações do contexto social e natural. Por isso, ações motivadas por boas intenções podem ter resultados negativos e ações mal-intencionadas, consequências positivas. A compreensão da ação requer a interação das lógicas auto e eco, os dois princípios da ecologia da ação ${ }^{23}$.

A eficácia ótima de uma ação situa-se no início de seu desenvolvimento, antes de ser arrastada à deriva no jogo das inter-retroações que a empurram para direções diferentes e até contrárias. Os efeitos da ação dependem das intenções do ator e, também, das condições do meio cultural e social onde acontece. Por isso, as últimas consequências de um ato não são previsíveis, decorrendo a incerteza de seu resultado. Daí a necessidade de superação da pseudoética maniqueísta, para considerar os riscos de qualquer ação poder inverter sua finalidade sem que o agente tome consciência disto.

A consciência das retroações, eventualidades e riscos torna possível concentrar-se no problema central de qualquer ação, a estratégia, e darse conta da ecologia das ideias (ecologia mental) onde acontece a ação necessária para sua eficá- 
cia. Essa segunda tensão, típica da ação humana, indica a importante e necessária atenção à dimensão estratégica da ética. Agir eticamente é agir estrategicamente $^{23}$. É claro que esse princípio não pode ser visto como reformulação da máxima de que o fim justifica os meios, numa aplicação da racionalidade instrumental à ética. O princípio corresponde à preocupação de que boas intenções podem produzir resultados não desejados e intencionados, quando faltam atenção, consciência e estratégia para assumir responsavelmente as consequências das ações.

A necessidade da estratégia na ação indica o vínculo entre conhecimento e ética. Quanto maior for a consciência sobre o contexto das inter e retrodependências onde acontece a ação, mais eficácia pode se esperar dos resultados. Portanto, é urgente a ética do conhecimento e, mais especificamente, a ética do enfoque transdisciplinar do conhecimento. A bioética hermenêutica está atenta a estratégias de mais longo alcance, para tomar consciência das inter e retrorreferências simbólicas das ações demandadas pelas biotecnologias e realizar uma ética do conhecimento aplicada à vida, à saúde e ao ambiente.

A complexidade da saúde e das ações relativas à vida e à saúde reflete os condicionantes dos atuais modos de subjetivação e do ambiente sociocultural das realidades que determinam interações e emergências, só captadas pela visão transdisciplinar.

\section{Transdisciplinaridade}

A racionalidade instrumental cartesiana levou o conhecimento científico à multiplicação e à diferenciação de disciplinas que dificultaram a visão de conjunto da realidade, pois o todo não é mera soma das partes e a estrutura de organização das partes no todo não é captada por um saber compartimentalizado. A constatação da fragilidade da racionalidade da ciência moderna provocou a busca de conexões entre as diferentes disciplinas científicas, resultando a multidisplinaridade, a pluridisciplinaridade, a interdisciplinaridade e a transdisciplinaridade.

Na multidisciplinaridade, diferentes disciplinas tratam do mesmo assunto sem estabelecer relações de cooperação entre seus saberes, numa simples justaposição de conhecimentos. A pluridisciplinaridade é a associação de diferentes disciplinas com efetivas relações de contribuição entre seus saberes, numa complementariedade, mas sem a constituição de axiomas comuns. Por exemplo, as discussões de equipe sobre casos clí- nicos. Interdisciplinaridade auxiliar é a interação de diversas disciplinas sob o comando de uma delas como campo integrador e coordenador dos diferentes conhecimentos. Na metadisciplinaridade, a integração entre as disciplinas é feita por uma metadisciplina, epistemologicamente, acima das demais. Na ciência moderna, esse foi o papel da matemática como linguagem formalizada; na saúde, isso coube à clínica. A interdisciplinaridade implica a existência de axiomas comuns a um grupo de disciplinas conexas, cujas relações definem-se por uma delas, que tem papel superior como disciplina integradora. É estrutural com reciprocidade, enriquecimento mútuo e horizontalização das relações. Na transdisciplinaridade, a integração das disciplinas exige a formação de uma axiomática geral compartilhada e implica a criação de um novo campo de conhecimento para fundamentação teórica e metodológica das disciplinas integradas. São exemplos: a ecologia e a saúde mental ${ }^{24}$.

Questionando este esquema, Almeida ${ }^{24}$ afirma que a integração interdisciplinar se dá mais pelos elementos simbólicos intraparadigmáticos do que pela constituição de uma axiomática comum. Assim, a interação não acontece ao nível das disciplinas, mas dos sujeitos que desenvolvem a prática científica, fundados em pressupostos mentais e institucionais. Como os sujeitos são agentes sociais de comunidades científicas estruturadas em matrizes de pensamento com poder social, as relações interdisciplinares são mais de conflito do que de diálogo. A integração entre os saberes acontece na disputa pela hegemonia de um paradigma dentro do campo disciplinar. Isso impossibilita a comunicação interdisciplinar, pois não se trata apenas da formulação de axiomas e postulados como bases para a integração, mas de integrar olhares e visões de mundo configuradores de paradigmas de pensamento, muitas vezes, antagônicos. Para tornar possível a interação dos saberes científicos é necessária uma mutação paradigmática capaz de transpassar as fronteiras disciplinares.

Com esse posicionamento crítico, Almeida ${ }^{24}$ redefine a transdisciplinaridade como a possibilidade de comunicação não entre campos disciplinares, mas entre agentes em cada campo, através da circulação não dos discursos, mas pelo trânsito dos sujeitos dos discursos. Segundo essa visão, não há campo científico mais transdisciplinar do que a saúde coletiva, nem objeto de conhecimento mais complexo, devido à diversidade de elementos que engloba. Ela é um daqueles objetos indisciplinados, não lineares, múlti- 
plos, plurais, emergentes e multifacetados que exigem dos pesquisadores um tratamento sintético e totalizante ${ }^{24}$ que abarca diferentes campos disciplinares como a epidemiologia, a clínica, a biologia e as ciências sociais. Sem ser exclusividade de nenhum destes, a saúde coletiva obriga seus operadores a transitarem entre os distintos saberes. Para isso, requer-se uma síntese paradigmática dos saberes que supere o paradigma científico clássico disciplinar; uma síntese transdisciplinar constituída pelo trânsito dos agentes científicos por diversos campos e saberes.

O Manifesto da Transdisciplinaridade de Basarab Nicolescu ${ }^{25}$ apresenta visão semelhante ao conceber a transdisciplinaridade desprovida de objeto por se encontrar entre as disciplinas, através das diferentes disciplinas e além de qualquer uma delas. Para captar esse não objeto identificável precisa-se um novo tipo de percepção. O paradigma científico configura a maneira de perceber o real e, então, há níveis de realidade não percebidos pelo paradigma científico vigente, por exemplo, a auto-organização das partes no todo, o real composto por ser e não ser, ordem e desordem. Existem níveis "trans" de realidade para os quais se exige uma transpercepção que ultrapasse a percepção disciplinarizada. A visão transdisciplinar só é possível com a percepção da realidade segundo o paradigma da complexidade. Por isso, a transdisciplinaridade não acontece ao nível dos objetos de conhecimento que ultrapassam as disciplinas, mas da percepção dos sujeitos operadores dos saberes científicos, tornando-se, então, essencialmente dependente de discussões sobre paradigmas e da introdução da ética do conhecimento.

Ser ético no uso e na produção do conhecimento significa explicitar os pressupostos que possibilitam sua formulação em pensamento. A ética do conhecimento transdisciplinar consiste em captar o subterrâneo do pensamento, visualizar o que está dissimulado no pensamento, ou seja, tornar conhecido o que transcende a formulação mental. Os bastidores do pensamento do paradigma contêm para todos os discursos que se realizam sob seu domínio, os conceitos fundamentais ou as categorias mestras de inteligibilidade, ao mesmo tempo, que o tipo de relações lógicas de atração/repulsão (conjunção, disjunção, implicação ou outras) entre esses conceitos e categorias ${ }^{26}$.

Assim, o paradigma contém as categorias mestras da inteligibilidade que determinam a seleção ou a rejeição das ideias a serem integradas ou descartadas no discurso e as operações lógi- cas mestras de inclusão ou exclusão, disjunção ou conjunção, implicação ou negação, segundo as características de sua verdade. Sob a lógica, esconde-se o paradigma controlador da conceitualização e da categorialização da mente e se determinam as hierarquias e as regras de inferência. $\mathrm{O}$ paradigma é infralógico (subterrâneo em relação à lógica), pré-lógico (anterior à sua utilização) e supralógico (superior a ela), controlando a lógica das proposições, dos discursos e das teorias. O paradigma aponta para a arqueologia do saber ${ }^{27}$.

Porém, o paradigma é vazio, sem conteúdo, porque nunca é formulado e não está inscrito em nenhuma parte. É, lembremos, sempre virtual. Só existe nas suas atualizações e nas suas manifestações. Só existe "paradigmaticamente", no exemplo que assinala a sua paternidade ${ }^{26}$. A ética do enfoque transdisciplinar consiste em tornar explícito e consciente, pelo conhecimento, o que está implícito, inconsciente no paradigma e determina a configuração do próprio conhecimento.

O pensamento simplificador da racionalidade instrumental não permite a consciência da noção de paradigma, pois elimina o sujeito da objetividade científica. A natureza do paradigma só pode ser percebida por um pensamento que reconheça a dialógica sujeito-objeto, a recursividade de causa e efeito e a multidimensionalidade aberta pela aceitação do terceiro incluído. Estas são características do pensamento complexo.

Aceitando que todo conhecimento é paradigmaticamente situado, tem-se clarividência sobre suas condições. Só um enfoque transdisciplinar educa para uma humildade cognitiva que conduz a esse posicionamento ético perante o conhecimento. O paradigma aponta, igualmente, para as possibilidades, limites e cegueiras do conhecimento. A incerteza faz parte do próprio conhecimento e são sempre possíveis as ilusões e contradições. Faz parte da ética do conhecimento dar-se conta das possibilidades e limites deste ${ }^{27}$.

A possibilidade do desvio ético liga-se à falta de consciência sobre possíveis ilusões e erros. Os desvios decorrem da falta de senso crítico e do conhecimento inadequado. As dificuldades do autoconhecimento e da autoanálise crítica correspondem à dificuldade de lucidez ética. A maior ilusão ética é crer que se obedece à mais alta exigência ética, quando, na verdade, se está agindo pelo mal e pela mentira ${ }^{27}$. A resposta ao desvio ético está na explicitação do paradigma em que o sujeito se move, dando conta dos pressupostos lógicos que fundamentam a maneira de compreender e de interpretar a realidade. 
A tomada de consciência do paradigma, no qual se constrói o conhecimento, é fruto da ruptura epistemológica e da ruptura promovida pela metodologia da ciência moderna, configurandose como epistemologia de segunda ordem que introduz a hermenêutica crítica e na qual ocupa lugar central, segundo Sotolongo ${ }^{28}$, a reflexividade do saber. Isso significa clarividência e transparência sobre os pressupostos e o paradigma que sustentam o discurso científico. Sua explicitação hermenêutica é problema epistemológico e, também, ético, da ética do conhecimento. A bioética, denominada por Sotolongo ${ }^{28}$ como saber transdisciplinário da complexidade referido às ações envolvendo a vida, a saúde e o ambiente, inserese nessa transição epistemológica e seu estatuto só pode ser entendido por meio da consideração dos elementos determinantes dessa transição. A bioética como hermenêutica crítica permite a reflexividade sobre os paradigmas presentes no saber em saúde, constituindo-se como uma ética do conhecimento por possibilitar maior transparência e clarividência dos pressupostos que movem os saberes e as práticas em saúde.

\section{Um estatuto epistemológico para bioética} na convergência com a saúde coletiva

O campo da saúde coletiva é diversificado, pois parte da concepção ampliada de saúde e move-se na interface de três distintos conhecimentos: as ciências sociais e humanas; a epidemiologia; a política e o planejamento em saúde. A inclusão das ciências sociais e humanas, novidade em relação ao modelo biomédico, foi consolidando-se como fundamental para a compreensão dos processos de saúde-doença, do adoecimento, da morte, dos processos de trabalho, dos cuidados e das relações profissionais ${ }^{6}$.

A bioética requer compreensão sociológica dos cuidados à saúde; entendimento psicológico e reconhecimento epidemiológico dos tipos de necessidades em saúde e da variedade de pressões às quais os profissionais estão sujeitos; compreensão histórica das teorias e práticas morais vigentes; conhecimento e destreza na aplicação de métodos de análise ética; reconhecimento epidemiológico dos perfis de problemas éticos relativos à vida, à saúde e ao ambiente; participação e conhecimento pessoal dos problemas éticos a que se propõe discutir, numa integração dos que se dedicam à bioética com os que estão na lida da saúde e do ambiente ${ }^{29}$.

Considerando as especificidades e as convergências entre saúde coletiva e bioética tem-se os elementos da transição epistemológica da qual ambas são fruto; as implicações do contexto e da subjetividade na definição da metodologia e na configuração de suas temáticas. A saúde coletiva significou a transição do modelo clássico biomédico para o paradigma que engloba os determinantes sociais e subjetivos no processo saúde, doença e cuidado. A bioética significou, igualmente, uma superação: do modelo de ética filosófica como análise formal da linguagem moral para o paradigma de ética aplicada que interpreta, com referência ao agir humano, as ações concretas relativas à vida, à saúde e ao ambiente. Ao referir-se às ações concretas inseridas em suas realidades, obrigatoriamente, a ética tem de ponderar em suas deliberações os determinantes subjetivos e contextuais das ações.

Quais as implicações dessa constatação para o estatuto epistemológico da bioética em sua interface convergente com a saúde coletiva?

A complexidade do objeto da saúde coletiva, os vínculos e as convergências da bioética com esse campo de conhecimentos e práticas remetem às questões epistemológicas relativas aos fundamentos e métodos desta que permitem caracterizar a interface entre estas enquanto forma de saber pertinente, fidedigno e legítimo ${ }^{2}$.

A proposta da saúde coletiva amplia a compreensão das políticas públicas de saúde em direção à promoção da saúde, ao retomar numa nova perspectiva as questões sanitaristas da medicina social e preventiva ${ }^{6}$. Estaria aí um norte para a bioética na sua interface com a saúde coletiva? A realidade complexa da saúde aponta para sua identificação com qualidade de vida e promoção do viver bem? Seriam estas questões para além da pura ética aplicada por incluírem o que vem a ser bem viver?

Abre-se a necessária interface entre saúde coletiva e bioética, apontando para a importância da perspectiva hermenêutica. A convergência da bioética com a saúde coletiva não se define apenas pela proximidade das temáticas que contemplam, mas pelo modo e pela metodologia para abordá-las.

A bioética e a saúde coletiva referem-se a conteúdos caracterizados pela complexidade e transdisciplinaridade, ao incluírem os determinantes sociais, subjetivos, contextuais e ambientais da saúde. Mais do que em épocas anteriores, a partir da modernidade, as ações humanas determinam-se pela subjetividade e pelo contexto sociocultural, o que dificulta sua avaliação moral. É preciso um modelo de ética apropriado a tal complexidade. 
Impõem-se, portanto, as perguntas: Que tipo de ética corresponde ao estatuto complexo e transdisciplinar da bioética, especialmente na sua convergência com a saúde coletiva? Que tipo de ética consegue, em sua avaliação, levar em consideração os determinantes subjetivos e socioculturais das ações humanas relativas à vida, à saúde e ao meio ambiente? Que tipo de ética dá conta de dialogar com o objeto complexo da saúde coletiva, como conhecimento e prática?

Os modelos de ética mais conhecidos na atualidade são: o modelo deontológico kantiano, caracterizado pela perspectiva crítica e fundamentação apriorística, e o modelo consequencialista utilitarista, baseado na facticidade (experiência) com uma análise pragmática não crítica. A complexidade dos determinantes subjetivos e socioculturais das ações humanas exige uma ética que seja crítica a partir da facticidade. A hermenêutica de Gadamer ${ }^{30,31}$ apresenta-se como proposta crítica a partir da facticidade, embora ele nunca tivesse se preocupado em sistematizar uma ética. $\mathrm{Na}$ modernidade, a ética e a hermenêutica não caminharam juntas, porque tinham diferentes pontos de vista: a crítica ou a facticidade. É possível propor uma ética hermenêutica que seja crítica a partir da facticidade?

Entender a complexidade moral das ações humanas em seus determinantes subjetivos e socioculturais significa tomar a experiência, a facticidade, como referência ética, pois é nela que estão sempre presentes e integrados. A experiência moral acontece na interseção do referencial simbólico de determinada comunidade moral com as coordenadas da subjetividade e do contexto sociocultural do agir, que definem o sentido de uma ação concreta. A análise interpretativa dessa concretização subjetiva e sociocultural do referencial simbólico na configuração do significado da ação representa a dimensão crítica e hermenêutica da ética, só possível com referência à facticidade ${ }^{32}$. A hermenêutica crítica da ação é o modelo de ética apropriado para a bioética, especialmente na interface com a saúde coletiva.

A hermenêutica é caminho privilegiado para o bioeticista, cujo papel se identifica mais com o interlocutor socrático do diálogo do que com o portador de respostas prontas, ao articular e facilitar o diálogo entre as partes, recordar aos participantes os contextos socioculturais e interpretar as perspectivas em jogo ${ }^{33}$.

A hermenêutica origina-se da abertura ao diálogo interpretativo. A racionalidade correspondente é prática, base para a deliberação. Ou seja, na deliberação acontece uma interpretação ou hermenêutica prática. $\mathrm{O}$ adjetivo "prática” não significa expertise técnica, mas sabedoria do vivido em determinado contexto. O intérprete prático é alguém inserido num contexto sociocultural, capaz de deliberar com os outros acerca do prudente em determinada situação. A interpretação prática identifica-se com a razão prática, a casuística e a hermenêutica. Pode ser chamada de discernimento, a designação atual para a prudência ou a frónesis aristotélica. O discernimento caracteriza-se por perceber ou detectar o que está em jogo, peneirar ou distinguir os diversos elementos implicados, optar pelo caminho mais adequado entre os vários que se apresentam. Discernir compreende o ver, o julgar e o agir; combina a profundidade da compreensão das exigências e a sensibilidade acurada pelas circunstâncias do contexto. O exercício de tal capacidade prática difere da pura aplicação de normas, pois é essencialmente pessoal e responsável ${ }^{34}$.

Exemplo dessa visão hermenêutica na bioética é a proposta deliberativa de Diego Gracia ${ }^{35,36}$ que mostra a semelhança entre os juízos morais e clínicos, entre a deliberação ética e a clínica. O exercício deliberativo clínico sempre é, ao mesmo tempo, exercício deliberativo ético. Ambos exigem-se e se engendram mutuamente. Falhas na deliberação clínica acabam por comprometer a deliberação ética, pois reduz o juízo a mera questão técnica baseada nas evidências objetivas dos exames laboratoriais ou dos dados estatísticos, epidemiológicos, no caso da saúde das populações ou grupos. Isso corresponde à tendência de reduzir problemas a dilemas devido à incapacidade de analisar a complexidade da situação clínica ou de saúde de determinado território ou grupo.

A racionalidade dilemática reduz as possibilidades de solução do problema a apenas duas, usando um caminho técnico para a decisão. A racionalidade problemática é deliberativa e só pesa os fatos, os valores, os deveres e as consequências envolvidos em cada uma das muitas possíveis saídas para solucionar um problema.

A deliberação moral requer escuta atenta; esforço para compreender a situação do caso; argumentos razoáveis para justificar os possíveis cursos de ação e a escolha feita; ajuda e orientação aos responsáveis pela decisão, que são os diretamente envolvidos no problema ético ${ }^{35,36}$.

O exercício hermenêutico na bioética, ou bioética hermenêutica, contribui para a reflexividade crítica da ação, interpretando os pressupostos éticos, antropológicos e socioculturais determinantes de como as realidades relativas ao meio ambiente, à vida e à saúde são configuradas, com- 
preendidas e tratadas na cultura e na sociedade atuais. Assim, o agir não se transforma em mero reflexo especular do contexto sociocultural, desatento aos significados e às consequências das ações $^{37}$.

$\mathrm{Na}$ prática, hermenêutica se dá, mais uma vez, a convergência entre bioética e saúde coletiva: compreender criticamente a realidade para interpretar o passado e projetar um futuro digno para todos, por meio de ações de corresponsabilização na preservação do meio ambiente, a promoção da saúde e dignidade humanas, tão vulneráveis e vulneradas no contexto sociocultural moderno.

\section{Conclusão}

A saúde coletiva e a bioética surgem no contexto da segunda ruptura epistemológica, ampliando a compreensão de suas temáticas correspondentes - a saúde e as ações humanas - com a inclu- são, em suas análises, dos determinantes ambientais e subjetivos antes rejeitados pela metodologia científica como parte do senso comum. Essa inclusão responde à complexidade de seus objetos que exige olhares transdisciplinares para sua abordagem.

Qual o efeito metodológico dessa constatação para o estatuto epistemológico da bioética na sua convergência com a saúde coletiva? A necessidade de assumir um modelo de ética capaz de incluir os determinantes ambientais e subjetivos das ações analisadas pela bioética, sendo coerente, ao mesmo tempo, com a especificidade da ética. Trata-se de integrar no modelo da ética tanto a facticidade quanto a criticidade, ou seja, ser crítico a partir da facticidade. A hermenêutica é o caminho para integrar esses dois elementos, tidos, em geral, como antagônicos para a ética. Por isso, o modelo apropriado de ética para a bioética, na interface com a saúde coletiva, é a hermenêutica crítica a partir da facticidade do contexto e da subjetividade.

\section{Colaboradores}

JR Junges e ELCP Zoboli participaram igualmente de todas as etapas de elaboração do artigo. 


\section{Referências}

1. Potter VR. Bioethics: bridge to the future. Englewood Cliffs: Prentice-Hall; 1971.

2. Schramm FR., Anjos MF, Zoboli ELCP, A questão das tendências epistemológicas ou de fundamentação. In: Anjos MF, Siqueira JE, organizadores. Bioética no Brasil. Tendências e perspectivas. Aparecida, São Paulo: Idéias \& Letras, Sociedade Brasileira de Bioética; 2007. p. 29-56.

3. Schramm FR. Cuidados em saúde da mulher e da criança, proteção e autonomia. In: Schramm FR, Braz M, organizadores. Bioética e Saúde: novos tempos para mulheres e crianças? Rio de Janeiro: Fiocruz; 2005. p. 39-65.

4. Bourdieu P. O Campo Científico. In: Ortiz R, organizador. Pierre Bourdieu. Coleção Grandes Cientistas Sociais: Sociologia. São Paulo: Ed. Ática; 1978. p. 122-155.

5. Paim JS, Almeida Filho N. Saúde Coletiva: uma "nova saúde pública" ou campo aberto a novos paradigmas? Rev Saude Publica 1998; 32(4):299-316.

6. Nunes ED. Saúde Coletiva: uma história recente de um passado remoto. In: Campos GWS, Minayo MCS, Akerman M, Drumond Júnior M, Carvalho YM, organizadores. Tratado de Saúde Coletiva. São Paulo, Rio de Janeiro: Hucitec, Fiocruz; 2006. p. 295-315.

7. Santos BS. Introdução a uma Ciência Pós-moderna. São Paulo: Ed. Graal; 2003.

8. Bachelard G. La Formation de l'Esprit Scientifique. Paris: Vrin; 1972.

9. Camargo Júnior KR. Biomedicina, Saber \& Ciência: uma abordagem crítica. São Paulo: Hucitec; 2003.

10. Cortina A, Martinez E. Ética. São Paulo: Ed. Loyola; 2005.

11. Moore GE. Principia Ethica. Cambridge: Cambridge University Press; 1980

12. Singer P, editor. Applied Ethics. New York: Oxford University Press; 1986

13. Morin E. Ciência e consciência. Rio de Janeiro: Bertrand Brasil; 2001.

14. Morin E. O Método 5: A Humanidade da Humanidade. A Identidade humana. Porto Alegre: Ed. Sulina; 2002.

15. Rozemberg B, Minayo MCS. A experiência complexa e os olhares reducionistas. Cien Saude Colet 2001; 6(1):115-123.

16. Almeida Filho N. La Ciencia Timida. Ensayos de deconstrucción de la epidemiologia. Buenos Aires: Lugar; 2000

17. Almeida Filho N. A saúde e o paradigma da complexidade. Cadernos IHU 4(15); São Leopoldo: Instituto Humanitas Unisinos; 2006

18. Almeida Filho N, Andrade RFS. Holopatogênese: esboço de uma teoria geral de saúde - doença como base para a promoção da saúde. In: Czeresnia D, Freitas CM, organizadores. Promoção da Saúde: conceitos, reflexões, tendências. Rio de Janeiro: Fiocruz; 2003. 97-115.

19. Samaja JA. A reprodução social e a saúde. Salvador: Ed. Casa de Qualidade; 2000

20. Samaja JA. Epistemología de la salud: Reproducción social, subjetividad y transdisciplina. Buenos Aires: Lugar Editorial; 2004
21. Campos GWS. Saúde Paidéia. São Paulo: Hucitec; 2005.

22. Cunha GT. A construção da clínica ampliada na atencão básica. São Paulo: Hucitec; 2005.

23. Morin E. O Método 6: Ética. Porto Alegre: Ed. Sulina; 2005

24. Almeida Filho N. Transdisciplinaridade e Saúde Coletiva. Cien Saude Colet 1997; 2(1/2):5-20.

25. Nicolescu B. O manifesto da transdisciplinaridade. São Paulo: TRIOM; 1999.

26. Morin E. O Método 2: A vida da vida. Porto Alegre: Ed. Sulina; 2001.

27. Morin E. O Método 3: O conhecimento do conhecimento. Porto Alegre: Ed. Sulina; 1999.

28. Sotolongo PL. El tema de la complejidad en el contexto de la bioética. In: Garrafa V, Kottow M, Saada A, coordenadores. Estatuto Epistemológico de la Bioética. México: Universidad Nacional Autónoma de México, Red Latinoamericana y del Caribe de Bioética de la UNESCO; 2005. p. 95-123.

29. Callahan D. Bioethics as discipline. In: Jecker NS, Jonsen AR, Pearlman RA, editors. Bioethics: An Introduction to the History, Methods and Practice. Boston: Jones \& Bartlett Publishers; 1997. p. 87-92.

30. Gadamer HG. Verdade e Método II: Complementos e índice. Petrópolis: Ed. Vozes; 2002.

31. Gadamer HG. Verdade e Método I: Traços fundamentais de uma Hermenêutica filosófica. 9a ed. Petrópolis: Ed. Vozes; 2008.

32. Conill SJ. Ética Hermenéutica. Crítica desde la facticidad. Madrid: Tecnos; 2006.

33. Leder D. Toward a hermeneutical bioethics. In: Dubose ER, Hamel RP, O'Connell LJ, organizadores. A Matter of Principles? Ferment in U.S. Bioethics. Valley Forge: Trinity Press International; 1994. p. 240-259.

34. Carson RA. Interpretive Bioethics: The way of discernment. Theoretical Medicine 1990; 11(1):51-59.

35. Gracia D. Moral deliberation: The role of methodologies in clinical ethics. Medicine, Health Care and Philosophy 2001; 4(2):223-232.

36. Gracia D. Ethical case deliberation and decision making. Medicine, Health Care and Philosophy 2003; 6(3):227-233

37. Junges JR. Bioética: Hermenêutica e Casuística. São Paulo: Ed. Loyola; 2006.

Artigo apresentado em 05/03/2010

Aprovado em 23/04/2010

Versão final apresentada em 05/05/2010 